\title{
The epidemiology of tuberculosis in Phuentsholing General Hospital: a six-year retrospective study
}

\author{
Kinley Wangdi and Manish Raj Gurung
}

\begin{abstract}
Background: This study was carried out to describe the epidemiology and treatment outcomes of TB infection in Bhutan at Phuentsholing General Hospital (PGH). Retrospective analysis of TB data was carried out using data from the TB registry of PGH from 2004-2009. Comparisons were made between TB, clinical presentation, diagnosis, and outcomes amongst male and female.

Findings: A total of 735 patients were analyzed, 12.4\% (91) of whom were children ( $\leq 14$ years). The highest cases was reported in 2009 (148), lowest in 2004 (93). Males and females were equally infected with TB. The median age was 25 years, (range 11 months - 98 years; IQR=20-35). Extra-pulmonary Tuberculosis (EPT) 62.6\% (57) was the commonest form of TB in children. Pleural effusion was more common in males 62.8\% (27) ( $p=0.013)$. Smear positive pulmonary tuberculosis (SPPT) 54.3\% (207) ( $p=0.02$ ) and treatment defaulted $84.2 \%(16)(p=0.004)$ was higher in males. However, transfer-in cases $57.0 \%(90)(p=0.036)$ and treatment outcome-failure $92.3 \%(12)$ $(p=0.002)$ were more in females than males. The cure rate for SPPT was $69.0 \%(293)$ and unknown treatment outcome for all forms of TB was 11.2\% (82).

Conclusion: TB infection has increased over the study period; SPPT increased more than other two forms of TB. The majority of the TB patients were in the age group of 15-34 years. Males and females were equally infected with TB and children made up $12.4 \%$ of TB patients. The cure rate amongst SPPT was $69 \%$, which is much lower than the national target of $85 \%$ set by National Tuberculosis Control Programme (NTCP). Further studies need to be undertaken to identify the risk factor for TB in the economically productive age group. There is a need for improvement in the services, recording and reporting so as to meet the target of cure rate of $85 \%$ in SPPT patients.
\end{abstract}

\section{Background}

Tuberculosis (TB) is a public health problem caused by Mycobacterium tuberculosis. World Health Organization (WHO) estimates that there are almost 13.7 million people living with $\mathrm{TB}$ and that the disease kills more young people and adults than any other infectious disease in the world [1]. A total of about 1.77 million people died of TB in 2007 including 456,000 patients infected with the Human Immunodeficiency Virus (HIV). TB is the seventh most common disease in the world and is the leading cause of death from curable diseases [2]. WHO declared TB a global health emergency in 1993 following dramatic changes in the magnitude of

\footnotetext{
*Correspondence: dockinley@gmail.com

Phuentsholing General Hospital, G.P.O. Phuentsholing, Chhukha, Bhutan
}

the problem. However, the number of new cases continues to increase and without a coordinated control effort, it is estimated TB will infect more than one billion people by 2020, with deaths reaching 36 million [3]. Various interrelated factors have been attributed to the resurgence of TB in recent years, including the HIV epidemic, ineffective control-programmes, population growth, and increased mobility of people [1,4-7].

In the South-East Asia Region (SEAR) of WHO, the annual incidence of TB is 3.17 million cases, with an estimated 4.88 million prevalent cases [8]. This amounts to one-third of the global burden of TB. Five of the 11 member countries in the region are among the 22 highburden countries, with India accounting for over $20 \%$ of the world's cases. Most cases occur in the age group of 15-54 years, with males being disproportionately
() Biomed Central

(C) 2012 Wangdi and Gurung; licensee BioMed Central Ltd. This is an Open Access article distributed under the terms of the Creative Commons Attribution License (http://creativecommons.org/licenses/by/2.0), which permits unrestricted use,

distribution, and reproduction in any medium, provided the original work is properly cited. 
affected. The male/female ratio among newly detected cases was 2:1. The deaths as a result of TB have declined after introduction of Directly Observed Treatment Short course chemotherapy (DOTS).

This study was carried out to describe the epidemiology and treatment outcomes of $\mathrm{TB}$ infection in Phuentsholing General Hospital (PGH). Tuberculosis disease, clinical presentation, diagnosis and outcomes amongst males and females were compared. The study was carried over six-month duration, from January to July 2011.

\section{Methods \\ Setting}

Phuentsholing General Hospital (PGH) is located in the Phuentsholing Municipality, under Chukha Dzongkhag. Phuentsholing Municipality is the second largest city, next to the capital city, Thimphu, in Bhutan. It is located $171 \mathrm{~km}$ south of the capital city, and it is the commercial hub of Bhutan. PGH is a fifty-bed hospital, with specialist services, including General Surgery and Obstetrics and Gynaecology, besides the general patient care. The hospital provides health care services to the people residing in Phuentsholing Municipality and other subdistricts of Phuentsholing and Sampheling; however, the population of two other sub-districts, Lochina and Dungna, also avail the diagnostic services at PGH.

\section{Tuberculosis control in Bhutan}

The National Tuberculosis Control Programme (NTCP) was initiated in $1976[9,10]$. NTCP is one of the programmes under the Department of Public Health. The NTCP has incorporated global targets and Millennium Development Goals (MDG) and developed the following objectives: (1) detect at least $70 \%$ of the estimated new smear-positive cases, (2) cure at least $85 \%$ of the newly diagnosed cases, (3) have halted and begun to reverse incidence of TB by 2015, and (4) halve the prevalence and death rate of TB between 1990 and 2015. Bhutan adopted the DOTS strategy in 1997. TB control and treatment was integrated into the general health care delivery system [9-11]. In line with the DOTS strategy, diagnosis is primarily based on sputum smear and chest $x$-ray. The resources for accurate diagnosis of TB are limited, and culture and drug susceptibility testing for M. tuberculosis have not been performed routinely.

The treatment regimen in Bhutan underwent many changes from 2004 to $2010[9,10]$. Before 2006, new SPPT and smear negative pulmonary tuberculosis (SNPT) seriously ill were treated with four drugs (streptomycin, isoniazid, rifampicin, and pyrazinamide) for two months of intensive therapy, and two drugs (isoniazid and ethambutol) in continuation therapy for another six months. SPPT relapse and failure cases were treated with five drugs (streptomycin, isoniazid, rifampicin, ethambutol and pyrazinamide) for two months of intensive therapy and four drugs (isoniazid, rifampicin, ethambutol and pyrazinamide) for one month, followed by three drugs (isoniazid, rifampicin, and ethambutol) for five months of continuation therapy. EPT was treated with three drugs (isoniazid, rifampicin, and pyrazinamide) in intensive therapy and two drugs (isoniazid and ethambutol) for six months in continuation therapy. However, since 2007, all new TB cases irrespective of their forms were treated with four drugs (isoniazid, rifampicin, ethambutol, and pyrazinamide) for two months of intensive therapy, and two drugs (isoniazid and ethambutol) in continuation therapy for another six months. In 2009, PGH contributed $9.9 \%$ of the total TB cases $(1,154)$ in Bhutan [12].

\section{Study design and data collection}

This study was carried out retrospectively using the data from the TB registry of PGH from 2004 to 2009. All the patients taking the anti-tuberculosis treatment (ATT) were recorded in the TB register and subsequently reported to the NTCP. Patients with symptoms such as fever and cough lasting more than three weeks, chest pain, haemoptysis, loss of weight, and loss of appetite, those suggestive of $\mathrm{TB}$, submitted three sputum samples: one spot and two on the subsequent days. Patients with at least two positive smears or one positive smear and radiologic abnormalities consistent with pulmonary tuberculosis, or one positive smear and sputum culture positive were considered to have SPPT. Those patients with three negative smears were treated with a course of antibiotic and evaluated subsequently. These latter patients were considered to have SNPT if they presented with a chest X-ray suggestive of pulmonary TB and did not response to antibiotics. The diagnosis of EPT was made based on the radiological, histological, or clinical evidence consistent with active $\mathrm{TB}$ in an extrapulmonary site.

Patients diagnosed with SPPT were admitted to the hospital for duration of two months for intensive therapy. All the patients were included in DOTS. Patients in other categories of TB- SNPT and EPT were admitted if the patients were ill or if they inhabited remote villages. All patients were offered anti-tuberculosis drugs free of charges because all the health care in Bhutan is provided free of charge. The patients underwent two months of intensive therapy followed by six months of a continuation phase. All TB patients submitted sputum samples for smear examination for acid fast bacilli (AFB) conversion at the end of second, fifth, and eight months, respectively.

Once patients were diagnosed as having TB, they were sent to the TB In-charge for recording and reporting. 
The information recorded in the TB register included: name, age, gender, address, type of infection (new, relapse, default, treatment failure, transferred in), type of TB (SPPT, SNPT, and EPT), treatment regimen, sputum conversion (2, 5, and 8 months), and treatment outcome (cured, completed treatment, defaulter, failure of treatment, died, or transferred out).

\section{Study population}

The study population for the present study was all the TB patients registered in PGH hospital from 2004 to 2009.

\section{Statistical analysis}

Data analysis was carried out using SPSS (version 10 for Microsoft Windows). Descriptive statistics (frequencies and means) were used to describe the demographic characteristics and treatment outcomes. Chi-square test and Fisher Exact test were used to find the association of different variables between male and female patients. The $p$-value of less than 0.05 was considered as significant.

\section{Ethical issues}

The ethical approval was obtained from the Research Ethical Committee of Health (RECH), Ministry of Health, Bhutan. To protect the privacy of the patients, the names of the patients were not included in case record form. Hospital numbers were not directly recorded, and it was delinked from the registration by using alternative number. The alternative number was used when some information was not entered correctly.

\section{Findings}

The total number of patients who received treatment for all forms of TB during the study period was 745. Due to the missing or incomplete information in 10 records, the cases that were included for the study were 735 . There was gradual increase in the number of cases over the study period with the highest cases reported in 2009 (148 cases) and the lowest number was recorded in 2004 (93 cases). SPPT increased from $36.6 \%$ (34) in 2004 to $60.8 \%$ (90) in 2009. However, the other two forms of TB; SNPT and EPT, decreased over the study period (Table 1).

Regarding the types of infection, new cases gradually reduced over the study period: $87.4 \%$ (81) in 2004, reducing to $69.6 \%$ (103) in 2009. Relapse case increased gradually over the study period, with highest number of cases reported in 2008 (10.9\%). Transfer-in cases increased from 9.9\% (9) in 2004 to 21.9\% (32) in 2009. The proportion of males to females remained the same throughout the study period, with equal numbers of males and females succumbing to $\mathrm{TB}$. $\mathrm{TB}$ in children

Table 1 Different forms of tuberculosis (TB), cases definitions, TB among gender, TB among the children and treatment outcome

\begin{tabular}{|c|c|c|c|c|c|c|}
\hline & 2004 & 2005 & 2006 & 2007 & 2008 & 2009 \\
\hline Tuberculosis in males (\%) & $44(47.1)$ & $49(46.7)$ & $76(57.1)$ & $63(47.7)$ & $67(54.0)$ & $70(47.3)$ \\
\hline \multicolumn{7}{|c|}{ TB cases by different age groups (years) $n(\%)$} \\
\hline $0-14$ & $20(21.5)$ & $19(18.1)$ & $16(12.0)$ & $12(9.1)$ & $10(8.1)$ & $14(9.5)$ \\
\hline $15-24$ & $18(19.4)$ & $31(29.5)$ & $45(33.8)$ & $46(34.8)$ & $53(42.7)$ & $54(36.5)$ \\
\hline $25-34$ & $21(22.6)$ & $25(23.8)$ & $43(32.3)$ & $36(27.3)$ & $35(28.2)$ & $50(33.8)$ \\
\hline $35-44$ & $11(11.8)$ & $11(10.5)$ & $9(6.8)$ & $15(11.4)$ & $13(10.5)$ & $11(7.4)$ \\
\hline $45-54$ & $9(9.7)$ & $9(8.6)$ & $8(6.0)$ & $13(9.8)$ & $32(2.4)$ & $6(4.1)$ \\
\hline$\geq 55$ & $14(15.1)$ & $10(9.5)$ & $12(9.0)$ & $10(7.6)$ & $10(8.1)$ & $13(8.8)$ \\
\hline All forms of TB (n) & 93 & 105 & 133 & 132 & 124 & 148 \\
\hline SPPT (\%) & $34(36.6)$ & $45(42.9)$ & $58(43.6)$ & $73(55.3)$ & $81(65.3)$ & $90(60.8)$ \\
\hline SNPT (\%) & $24(25.8)$ & $18(17.1)$ & $35(26.3)$ & $25(18.9)$ & $7(5.7)$ & $20(13.5)$ \\
\hline EPT (\%) & $35(37.6)$ & $42(40.0)$ & $40(30.1)$ & $34(25.8)$ & $36(29.0)$ & $38(25.7)$ \\
\hline \multicolumn{7}{|l|}{ Case definitions } \\
\hline New cases (\%) & $81(87.4)$ & $68(64.8)$ & $96(72.2)$ & $84(63.6)$ & $80(64.5)$ & $103(69.6)$ \\
\hline Relapse (\%) & $2(2.2)$ & $4(3.8)$ & $2(1.5)$ & $13(9.9)$ & $13(10.5)$ & $7(4.7)$ \\
\hline Transfer in (\%) & $9(9.9)$ & $33(31.4)$ & $30(22.6)$ & $30(22.7)$ & $24(19.4)$ & $32(21.6)$ \\
\hline Treatment after default (\%) & $1(1.1)$ & $0(0)$ & $2(1.5)$ & $3(2.3)$ & $1(0.8)$ & $6(4.1)$ \\
\hline Failure (\%) & $0(0)$ & $0(0)$ & $0(0)$ & $1(0.8)$ & $0(0)$ & $0(0)$ \\
\hline Others (\%) & $0(0)$ & $0(0)$ & $1(0.8)$ & $0(0)$ & $0(0)$ & $0(0)$ \\
\hline Unknown (\%) & $0(0)$ & $0(0)$ & $2(1.5)$ & $1(0.8)$ & $6(4.8)$ & $0(0)$ \\
\hline
\end{tabular}

SPPT- sputum positive pulmonary tuberculosis; SNPT- sputum negative pulmonary tuberculosis; EPT-extra-pulmonary tuberculosis. 
decreased from $21.5 \%$ (20) in 2004 to $9.5 \%$ (14) in 2009. Extra-pulmonary Tuberculosis (EPT) 62.6\% (57) was the commonest form of TB in children. The median age was 25 years, and the age range was 11 months to 98 years $(\mathrm{IQR}=20-35)$. The highest number of $\mathrm{TB}$ cases was reported among the 15-34 year-old age group 62.2\% (457).

\section{TB distribution between males and females}

TB between male and female was compared to investigate any differences in types of the disease, forms of TB, and treatment outcomes (Table 2). There were no differences between males and females for new cases and relapses. However, the number of transfer-in cases was higher among females than males, with $57.0 \%$ (90) to $43.0 \%(68)(p=0.036)$. SPPT was more common among males than females with $54.3 \%$ (207) to $45.7 \%$ (174) $(p=0.02)$. There was no difference of SNPT in either gender $(p=0.3)$. When different forms of EPT were compared; only pleural effusion was more common in males than females $62.8 \%(27)$ to $37.2 \%(16)(p=0.013)$. When comparing the treatment outcome among male and female,"Failures" and "defaulters" were observed to be significantly different between males and females. There were more treatment failures in females than males $92.3 \%(12)$ to $7.7 \%(1)(p=0.002)$; however, there were more male treatment defaulters than females $84.2 \%$ (16) to $15.8 \%(3)(p=0.004)$.

\section{Treatment outcome by types of infection}

The treatment outcomes of different forms of TB were compared (Table 3). The treatment cure rate for the SPPT cases was $69.0 \%$ (263) during the study period. Treatment completed was achieved in $16.3 \%$ (62) of SPPT, $70.5 \%$ (91) of SNPT, and 80.0\% (180) of EPT cases. The defaulter rate from all forms of infection during the study was $2.6 \%$ (19). However, defaulters were highest for the SNPT 3.1\% (4). Mortality from all forms of TB was $2.0 \%$ (15); the highest death rate was observed among SNPT patients 3.1\% (4). Treatment failure rate was highest for SPPT at 2.9\% (11). Treatment "outcome unknown" for all types of TB during the study period was $11.2 \%$ (82), and highest rate was reported for SNPT $20.2 \%(26)$.

\section{Discussion}

There was a gradual increase of $\mathrm{TB}$ over the study period. There was a significant increase in SPPT, with decrease in the other forms of TB, SNPT and EPT, over the six-year period. A number of plausible risk factors for TB infection such as, HIV infection, smoking, alcohol use, and other life style associated diseases such as diabetes and hypertension, malignancies, and chronic lung diseases have been reported in other researches,
Table 2 TB distribution between female and male by case definitions forms of TB and treatment outcome

\begin{tabular}{|c|c|c|c|c|}
\hline & Total & Female (\%) & Male (\%) & $P$ value \\
\hline \multicolumn{5}{|l|}{ Case definitions } \\
\hline New cases & 512 & $246(48.1)$ & $266(52.0)$ & 0.2 \\
\hline Relapse & 41 & $18(43.9)$ & $23(56.1)$ & 0.5 \\
\hline Transfer in cases & 158 & $90(57.0)$ & $68(43.0)$ & 0.036 \\
\hline Treatment after default & 13 & $5(38.5)$ & $8(61.5)$ & 0.58 \\
\hline \multicolumn{5}{|l|}{ Forms of TB } \\
\hline SPPT & 381 & $174(45.7)$ & $207(54.3)$ & 0.02 \\
\hline SNPT & 129 & $70(54.3)$ & $59(45.7)$ & 0.3 \\
\hline \multicolumn{5}{|l|}{ EPT } \\
\hline TB lymphadenitis & 43 & $26(60.5)$ & $17(39.5)$ & 0.36 \\
\hline TB osteomyelitis & 7 & $2(28.6)$ & $5(71.4)$ & 0.25 \\
\hline Pleural effusion & 43 & $16(37.2)$ & $27(62.8)$ & 0.013 \\
\hline \multicolumn{5}{|l|}{ Treatment outcome } \\
\hline Cured & 263 & $127(48.3)$ & $136(51.7)$ & 0.54 \\
\hline Treatment completed & 333 & $169(50.8)$ & $164(49.3)$ & 0.64 \\
\hline Death & 15 & $9(60.0)$ & $6(40.0)$ & 0.43 \\
\hline Failure & 13 & $12(92.3)$ & $1(7.7)$ & 0.002 \\
\hline Defaulted & 19 & $3(15.8)$ & $16(84.2)$ & 0.004 \\
\hline Stopped & 4 & $2(50.0)$ & $2(50.0)$ & 1.0 \\
\hline Transferred out & 6 & $4(66.7)$ & $2(33.3)$ & 0.45 \\
\hline Outcome unknown & 82 & $40(48.8)$ & $42(51.2)$ & 0.85 \\
\hline
\end{tabular}

SPPT- sputum positive pulmonary tuberculosis; SNPT- sputum negative pulmonary tuberculosis; EPT-extra-pulmonary tuberculosis.

but could not be covered in this study [13-15]. However, some of plausible reasons for increased TB cases in PGH could be rapid urbanization and crowding, with related poor sanitation and malnutrition. There is inadequate housing in Phuentsholing, with many people residing in the Indian town of Jaigon, West Bengal. Poor socioeconomic conditions have been identified as the main risk factors associated with the transmission of $\mathrm{TB}$

Table 3 Treatment outcome by types of infection

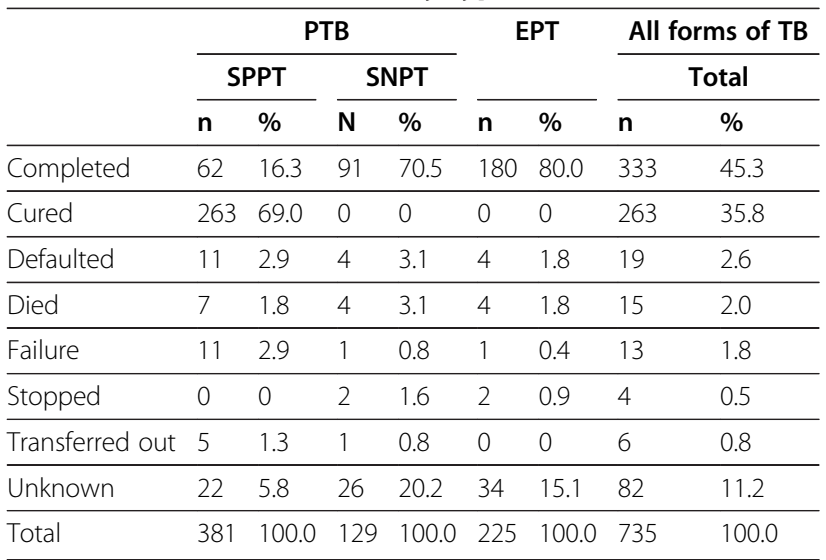

SPPT- sputum positive pulmonary tuberculosis; SNPT- sputum negative pulmonary tuberculosis; EPT-extra-pulmonary tuberculosis. 
[16]. Other reasons, such as increased awareness of TB, could have lead to more people seeking medical care. Improved health care services with improved diagnostic facilities for TB may also contribute to the higher number of detected cases. Similar reasons have been discussed by Jetan et al. in Malaysia [17]. People living with HIV/AIDS (PLWHA) in Phuentsholing are second highest number of those infected in the country. HIV increases the susceptibility to TB by many times [18]. This could be one of the plausible reasons for increasing TB cases in Phuentsholing. However, HIV status of the TB patients under study was not available, despite all TB patients were offered voluntary counselling and testing (VCT) services at the hospital.

The majority of cases $62.2 \%$ (457) were in the 15-34 year-old age group. The younger people are increasingly changing their life style and are involved in unhealthy lifestyle and practices, such as eating junk and less nutritious food, increased use of alcohol, tobacco and drugs thus providing opportunities for latent TB to reactivate into active infection. However, the underlying risk factor for increased TB in age group 15-34 years was not covered in the present study and it is imperative that these risk factors be explored further in future so that programme can develop strategies and policies to reduce TB infection in this age group. Jeten et al. reported that the higher cases of TB among the productive age group were a result of employment, whereby infection was exposed at the work place [17]. This could be possible in Phuentsholing as well since there are huge employment opportunities in Pasakha Industrial Estate and Phuentsholing town. Children made up to $12.4 \%$ of TB cases during the study period. The finding that children presented commonly with EPT $62.6 \%$ is consistent with other studies, and it has been associated with the difficulty in collection of sputum in children [19].

\section{TB distribution between males and females}

There were equal numbers of males and females succumbing to TB. Similar findings have been reported in the literature, suggesting that the access to and use of healthcare services is similar in men and women [20]. While other research has reported higher male compared with female TB infection due to differential health seeking behaviour, stigma associated to TB infection, and barriers to health care [21-23].

Higher rates of SPPT among males compared with females were noted in the present study. Some of the plausible reasons could be as a result of infection acquired outside in a crowded, poorly ventilated work setting. The male population usually work outside such as farms and factories, while females work at the home. Males are also more likely to report risk factors such as frequent use of alcohol and tobacco, important deterrents for latent TB infection progression to active TB. However, these risk factors were not covered in the present study. More transfer-in cases were observed among females. This could be as a result of the people migrating to Phuentsholing for businesses and job opportunities as explained earlier because Phuentsholing is the commercial hub of Bhutan. Males were more likely to default from treatment, and similar findings had been found in other studies [20]. Higher cases of pleural effusion were found among men in this study; however, other studies showed that pleural effusion was more common in females, contrary to the findings of this study [24]. Other studies reported higher defaulter and failure rates among males; however, in this studies treatment failure were more common in females whereas, the defaulters observed to be higher among males [20].

\section{Treatment outcomes}

The treatment outcome - cured for new SPPT cases during the study was $69.0 \%$, which is lower than the national target of $80 \%$ and the national cure rate of $89 \%$ in $2007[9,10,25]$. Some of the reasons for not being able to achieve the national target could be poor follow-up as a result of gaps in human resources as well as due to the migrant nature of the population/floating population availing the services from PGH. High treatment failure in SPPT needs to be further explored because this can lead to development of multi-drug resistant (MDR) TB. There was a significant percentage $11.2 \%$, with unknown treatment outcome, which indicated poor follow-up and default tracing.

\section{Limitations}

These findings were subject to at least five limitations. First, sociological data were not available, and the information that was available, recovered from registers, may be imprecise in some cases. Second, the present study was unable to access the available data on HIV status. Third, there is no facility for drug sensitivity test (DST). Fourth, the treatment regimens changed during the period of study, and this may contribute to the results found. Fifth, some of the findings of this study may not necessarily reflect national trends because the study was based on the patients diagnosed and treated in PGH.

\section{Conclusions}

In conclusion, there was a gradual increase in TB infection over the study period. The increase was more in SPPT as compared to other two forms of TB-SNPT and EP. New cases represented the majority of patients over the study period. The majority of the TB patients were in the economically productive age group of 15-34 years. There is a need to identify the underlying cause for this finding. This could enable the programme to develop 
strategies and policies to reduce TB infection in the age group of 15-34 years. Equal numbers of males and females succumbed to TB. SPPT was more common among males than females while there was no difference of SNPT in either gender. Pleural effusion was more common in males than females when EPT was compared. Treatment failures were more in females than males, while more males defaulted from treatment. Children made up $12.4 \%$ of $\mathrm{TB}$ patients. The cured rate amongst SPPT was 69\%, much lower that the national target of $85 \%$ set by NTCP. The treatment outcome unknown was $11.2 \%$ indicating poor follow up and monitoring. There is an urgent need for improvement in the recording and reporting with adequate human resource allocation.

\section{Competing interests}

The authors declare there were no competing interests.

\section{Authors' contributions}

KW conceived the research aim, and undertook the data collection, statistical analysis, and drafting of manuscript. MRG was involved in the critical analysis and drafting of this manuscript. Both authors read and approved the final version.

\section{Acknowledgements}

We would like to thank Ministry of Health, Royal Government of Bhutan for allowing us to use the data. We would also like to thank Dr. Stephen King for proof reading and writing of the manuscript and Dr. Myo Nyein Aung for giving his valuable comments and suggestions while writing this paper. Our special thanks go to Mrs. Chhimi Dema, Medical Record Technician of PGH, for helping in data extraction, and Mrs. Maya Thapa, In-charge of TB Unit, PGH who helped us in data extraction and data cleaning.

Received: 31 August 2011 Accepted: 12 June 2012

Published: 20 June 2012

\section{References}

1. World Health Organization: Global tuberculosis control: epidemiology, strategy, financing. Geneva: WHO report; 2009.

2. Murray CJL, Lopez AD: Global mortality, disability, and the contribution of risk factors: Global Burden of Disease Study. The Lancet 1997, 346:1436-1442.

3. Murray CIL, Lopez AD: The global burden of disease: a comprehensive assessment of mortality and disability from diseases, injuries and risk factors in 1990 and projected to 2020: summary. Geneva; 1996.

4. Jansen PA, Lambert LA, Indemarco MF, Ridzon R: CDC. Guidelines for preventing the transmission of Mycobacterium tuberculosis in healthcare settings, 2005. MMWR Recomm Rep 2005, 54(17):1-141.

5. American Lung Association: Tuberculosis. http://www.lungusa.org/lungdisease/tuberculosis/.

6. Coker R: Migration, public health and compulsory screening for tuberculosis and HIV: Asylum and Migration Working Paper 1. Public Policy Research: Institute for; 2003.

7. Davies PDO: The world wide increase in tuberculosis: how demographic changes, HIV infection and increasing numbers in poverty are increasing tuberculosis. Ann Med 2003, 35:235-243.

8. TB in South-East Asia. http://www.searo.who.int/en/Section10/Section2097/ Section2100_10639.htm.

9. Ministry of Health: Guidelines for National Tuberculosis Control Programme, $3^{\text {th }}$ edition. Bhutan: Thimphu; 2005.

10. Ministry of Health: Guidelines for National Tuberculosis Control Programme. Thimphu: 4th edition; 2007

11. Ministry of Health: Annual Health Bulletin 2008. Thimphu; 2009

12. Ministry of Health: Annual Health Bulletin 2010. Thimphu; 2011.
13. Christopoulos Al, Dimopoulos AA, Dimopoulos PA, Goumenos DS, Barbalias $\mathrm{GA}$ : Risk factors for tuberculosis in dialysis patients: a prospective multicenter clinical trial. BMC Nephrol 2009, 10:36.

14. Pablos-Mendez A, Blustein J, Knirsch C: The role of diabetes mellitus in the Higher Prevalence of Tuberculosis among Hispanics. Am J Public Health 1997, 87:4.

15. Stevenson CR, Forouhi N, Roglic G, Williams BG, Lauer JA, Dye C, Unwin N: Diabetes and tuberculosis: the impact of the diabetes epidemic on tuberculosis incidence. BMC Public Health 2007, 7:234.

16. Gutiérrez MC, Vincent V, Aubert D, Bizet J, Gaillot O, Lebrun L, Le Pendeven C, Le Pennec MP, Mathieu D, Offredo C, Pangon B, Pierre-Audigier C: Molecular Fingerprinting of Mycobacterium tuberculosis and Risk Factors for Tuberculosis Transmission in Paris, France, and Surrounding Area. J Clin Micro 1998, 36:486-492.

17. Jetan CA, Jamaiah I, Rohela M, Nissapatrn V: Tuberculosis: an eight year (2000-2007) retrospective study at the university of Malaya medical centre (UMMC), Kuala Lumpur, Malaysia. Southeast Asian J Trop Med Public Health 2010, 41:378-385.

18. Datiko DG, Yassin MA, Chekol LT, Kabeto LE, Lindtjørn B: The rate of TB-HIV co-infection depends on the prevalence of HIV infection in a community. BMC Public Health 2008, 8:266.

19. Satyanarayana S, Shivashankar R, Vashist RP, Chauhan LS, Chadha SS, Dewan PK, Wares F, Sahu S, Singh V, Wilson NC, Harries AD: Characteristics and Programme-Defined Treatment Outcomes amongst Childhood Tuberculosis (TB) Patients under the National TB Programme in Delhi. Plos One 2010, 5:10.

20. Jiménez-Corona ME, García-García L, DeRiemer K, Ferreyra-Reyes L, Bobadilla-del-Valle M, Cano-Arellano B, Canizales-Quintero S, MartínezGamboa A, Small PM, Sifuentes-Osornio J, Ponce-de-León A: Gender Differentials of pulmonary tuberculosis transmission and reactivation in an endemic area. Thorax 2006, 61:348-353.

21. Sreeramreddy CT, Panduru KV, Verma SC, Joshi HS, Bates MN: Comparison of pulmonary and extrapulmonary tuberculosis in Nepal- a hospitalbased retrospective study. BMC Inf Dis 2008, 8:8.

22. Holmes $C B$, Hausler $H$, Nunn P: A review of sex differences in the epidemiology of tuberculosis. Int J Tuberc Lung Dis 1998, 2:96-104.

23. Hudelson P: Gender differentials in tuberculosis: the role of socioeconomic and cultural factors. Tuber Lung Dis 1996, 77:391-400.

24. Noertjojo K, Tam CM, Chan SL, Chan-Yeung MMW: Extra-pulmonary and pulmonary tuberculosis in Hong Kong. Int J Tuberc Lung Dis 2002, 6:879-886.

25. WHO: Tuberculosis control in the South-East Region. Delhi: The Regional Report; 2011.

doi:10.1186/1756-0500-5-311

Cite this article as: Wangdi and Gurung: The epidemiology of

tuberculosis in Phuentsholing General Hospital: a six-year retrospective study. BMC Research Notes 2012 5:311.

\section{Submit your next manuscript to BioMed Central and take full advantage of:}

- Convenient online submission

- Thorough peer review

- No space constraints or color figure charges

- Immediate publication on acceptance

- Inclusion in PubMed, CAS, Scopus and Google Scholar

- Research which is freely available for redistribution 